\title{
Fuzzy Evaluation for the Rate of Aggregative Risk in Software Development
}

\author{
LILY LIN ${ }^{1)}$, HUEY-MING LEE ${ }^{2)}$, SHU-YEN LEE ${ }^{3)}$, TSUNG-YEN LEE ${ }^{4)}$ \\ 1) Department of International Business, China University of Technology \\ 56, Sec. 3, Hsing-Lung Road, Taipei (116), TAIWAN \\ ${ }^{2)}$ Department of Information Management, Chinese Culture University \\ 55, Hwa-Kung Road, Yang-Ming-San, Taipei (11114), TAIWAN \\ ${ }^{3)}$ Dep. of Private Participation in Infrastructure, China Engineering Consultants, \\ Inc. 5Fl., 300, Sec. 4, ChungHsiao E. Road, Taipei 10694, Taiwan \\ 4) SinoPac Holding, 2Fl., No. 306, Sec. 2, Bade Road, Taipei 104, Taiwan
}

\begin{abstract}
In this paper, we present a new fuzzy assessment method to tackle the rate of aggregative risk in fuzzy circumstances by fuzzy sets theory during any phase of the software development life cycle. Because the proposed method directly uses the fuzzy numbers rather than the linguistic values to evaluate, it can be executed much faster than before. The proposed fuzzy assessment method is easier, closer to evaluator real thinking and more useful than the ones they have presented before.
\end{abstract}

Key-Words: - Fuzzy assessment; Risk analysis; Rate of aggregative risk.

\section{Introduction}

During the past decades, computer technologies have changed so fast that the need of large software system becomes much more intensive. Most of the cost evaluations are characterized by high uncertainty. Thus, there are many problems occur in the software system development life cycle, such as postponed schedule, increased cost, inefficiency and abandonment [10].

Generally, risk is the traditional manner of expressing uncertainty in the systems life cycle. In a quantitative sense, it is the probability at such a given point in a system's life cycle that predicted goals can not be achieved with the available resources. Due to the complexity of risk factors and the compounding uncertainty associated with future sources of risk, risk is normally not treated with mathematical rigor during the early life cycle phases [1].

Risks result in project problems such as schedule and cost overrun, so risk minimization is a very important project management activity [13]. Up to now, there are many papers investigating risk identification, risk analysis, risk priority, and risk management planning [1-5, 8]. Conger [7] presented a list of possible software risks.
In evaluating the rate of risk factors, most decision-makers or project-managers, in fact, viewed those factors as linguistic values (terms), e.g., very high, high, middle, low, very low and etc. After fuzzy sets theory was introduced by Zadeh [14] to deal with problem in which vagueness is present, linguistic value can be used for approximate reasoning within the framework of fuzzy set theory [15] to effectively handle the ambiguity involved in the data evaluation and the vague property of linguistic expression, and normal triangular fuzzy numbers are used to characterize the fuzzy values of quantitative data and linguistic terms used in approximate reasoning.

Therefore, Lee [10] classified the risk factors presented by Boehm [2-4], Charette [5], Conger [7], Gilb [8] into six attributes, divided each attribute into some risk items, built up the hierarchical structured model of aggregative risk and the evaluating procedure of structured model. Lee [10] ranged the grade of risk for each risk item into eleven ranks, and presented the procedure to evaluate the rate of aggregative risk using two stages fuzzy assessment method. Chen [6] proposed the other arithmetic operations instead of the two stages fuzzy assessment 
method, and defuzzified the trapezoid or triangular fuzzy numbers by the median. Based on [6, 10], Lee et al. [11] proposed the other algorithm to evaluate the rate of aggregative risk.

In previous studies [6, 10-11], they used eleven or thirteen linguistic values for ranking the grades of risk to each risk item, where the linguistic values were represented by the triangular fuzzy numbers. But, it is very complicated to compute. Also, the evaluator only chooses one grade from grades of risk for each risk item. It has difficulty in reflecting the evaluator's incomplete and uncertain thought. Therefore, if we use fuzzy sense of assessment to express the degree of evaluator's feelings based on his own concepts, the results will be closer to the evaluator's real thought.

\section{The Proposed Fuzzy Assessment Method}

We present the fuzzy assessment method as follows:

\section{Step 1: Assessment form for the risk items:}

The criteria ratings of risk are linguistic variables with linguistic values, $V_{1}, V_{2}, \ldots, V_{7}$, where $V_{1}=$ extra low, $V_{2}=$ very low, $V_{3}=$ low, $V_{4}=$ middle, $V_{5}=$ high,$V_{6}=$ very high, $V_{7}=$ extra high .

In previous studies [6, 10-11], the evaluator only chooses one grade from grade of risk for each risk item, it ignores the evaluator's incomplete and uncertain thinking. Therefore, if we use fuzzy numbers of assessment in fuzzy sense to express the degree of evaluator's feelings based on his own concepts, the computing results will be closer to the evaluator's real thought.

The assessment for each risk item with fuzzy number can reduce the degree of subjectivity of the evaluator, express the degree of evaluator's feelings based on his own concepts. The results will be closer to the evaluator's real thought. Based on the structured model of aggregative risk and evaluating form of structured model proposed by Lee [10], we proposed the new assessment method of the structured model as shown in Table 1.

In Table 1

$$
\sum_{i=1}^{6} W_{2}(i)=1, \quad 0 \leq W_{2}(i) \leq 1
$$

, for each $i=1,2, \ldots 6$.

$$
\sum_{i=1}^{n(k)} W_{1}(k, i)=1, \quad 0 \leq W_{1}(k, i) \leq 1
$$

for $k=1,2, \ldots, 6 ; \mathrm{n}(1)=1, \mathrm{n}(2)=4, \mathrm{n}(3)=2, \mathrm{n}(4)=4$, $\mathrm{n}(5)=2, \mathrm{n}(6)=1 ; i=1,2, \ldots, \mathrm{n}(\mathrm{k})$.

$$
\sum_{l=1}^{7} m_{k i}^{(l)}=1,0 \leq m_{k i}^{(l)} \leq 1
$$

, for $l=1,2, \ldots, 7 ; k=1,2, \ldots, 6 ; i=1,2, \ldots, \mathrm{n}(\mathrm{k})$.

From Table 1, we directly use the fuzzy numbers $\left(m_{k i}^{(l)}\right)$ rather than the linguistic values to evaluate. Also, we may express the risk item $X_{k i}$ as fuzzy discrete type

$X_{k i}=\frac{m_{k i}^{(1)}}{V_{1}} \oplus \frac{m_{k i}^{(2)}}{V_{2}} \oplus \frac{m_{k i}^{(3)}}{V_{3}} \oplus \frac{m_{k i}^{(4)}}{V_{4}} \oplus \frac{m_{k i}^{(5)}}{V_{5}} \oplus \frac{m_{k i}^{(6)}}{V_{6}} \oplus \frac{m_{k i}^{(7)}}{V_{7}}$

\section{Step 2: By the first stage aggregative assessment}

Based on [10], by the centroid method, we have the $\operatorname{VG}(1)=0.0556, \operatorname{VG}(2)=0.1667, \mathrm{VG}(3)=$ 0.3333, VG(4) $=0.5, \mathrm{VG}(5)=0.6667, \mathrm{VG}(6)=$ $0.8333, \operatorname{VG}(7)=0.9444$ as center of mass of $V_{1}, V_{2}$, $V_{3}, V_{4}, V_{5}, V_{6}, V_{7}$, respectively. Let $\mathrm{V}=\left\{V_{1}, V_{2}, V_{3}\right.$, $\left.V_{4}, V_{5}, V_{6}, V_{7}\right\}$ be the set of the criteria rating of risk for each risk item. By fuzzy relation on $X_{i} \times V$, we can form a fuzzy assessment matrix $\mathrm{M}\left(\mathrm{X}_{\mathrm{i}}\right)$ for $X_{i} \times V \quad[10,16]$ for $i=1,2, \ldots, 6$.

Evaluate the first stage aggregative assessment risk for attribute $X_{i}$ as follows:

$$
\begin{aligned}
& (R(i, 1), R(i, 2), R(i, 3), \ldots, R(i, 7)) \\
& =\left(W_{1}(i, 1), W_{1}(i, 2), \ldots, W_{1}(i, n(i))\right) \times M\left(X_{i}\right)
\end{aligned}
$$


for $i=1,2, . ., 6$

We denote $\quad R_{1}(i)=(R(i, 1), R(i, 2), R(i, 3), \ldots, R(i, 7))$

the vector of the first stage aggregative assessment for attribute $X_{i}$ for $i=1,2, \ldots, 6$.

\section{Step 3: By the Second Stage Assessment}

The algorithm of the second stage assessment is

$$
=\left(W_{2}(1), W_{2}(2), \ldots, W_{2}(6)\right) \times\left(\begin{array}{c}
R_{1}(1) \\
R_{1}(2) \\
R_{1}(3) \\
R_{1}(4) \\
R_{1}(5) \\
R_{1}(6)
\end{array}\right)
$$$$
\text { ( } \left.R_{2}(1), R_{2}(2), R_{2}(3), R_{2}(4), R_{2}(5), R_{2}(6), R_{2}(7)\right)
$$

, where $R_{2}(i)=\sum_{k=1}^{6} W_{2}(k) \times R(k, i)$, for $\mathrm{i}=1,2, \ldots, 7$.

\section{Step 4: Defuzzified by the centroid method}

Defuzzified ( $R_{2}(1), R_{2}(2), R_{2}(3), R_{2}(4), R_{2}(5), R_{2}(6)$, $R_{2}(7)$ ) in Eq. (6) by the centroid method, we have that the rate of aggregative risk for the evaluator's assessing is as follows:

$$
\text { Rate }=\frac{\sum_{i=1}^{7} V G(i) \cdot R_{2}(i)}{\sum_{k=1}^{7} R_{2}(k)}=\sum_{i=1}^{7} V G(i) \cdot\left(\frac{R_{2}(i)}{\sum_{k=1}^{7} R_{2}(k)}\right)
$$

The value of Rate is the rate of aggregative risk in software development.

\section{Numerical Example}

Assume that we have the following attributes, weights, grade of risk for each risk item as shown in Table 2.

By the evaluating process shown in Section 2, we have

$$
\begin{aligned}
& \text { (R2(1), R2(2), R2(3), R2(4), R2(5), R2(6), R2(7)) } \\
& =(0.0258,0.357,0.5982,0.019,0,0,0)
\end{aligned}
$$

Defuzzyfied by the centroid method as shown in Eq. (8), we have
Rate $=0.26983$

i.e., the rate of aggregative risk is 0.26983 .

\section{Conclusion}

In general survey forces evaluator to assess one grade from the grade of risk to each risk item, but it ignores the uncertainty of human thought. For instance, when the evaluator need to choose the assessment from the survey which lists eleven choices including "definitely unimportant”, "extra unimportant”, "very unimportant”, “unimportant”, "slightly unimportant”, "middle”, "slightly important”, “important”, "very important”, “extra important", and "definitely important", the general survey becomes quiet exclusive. The assessment of evaluation with fuzzy numbers can reduce the degree of subjectivity of the evaluator. In this paper, we propose a new assessment method to evaluate the rate of aggregative risk in software development. Because the proposed method directly uses the fuzzy numbers rather than the linguistic values to evaluate, it can be executed much faster. Therefore, the evaluator can assess the risk grade by fuzzy numbers to each risk item, which making evaluation process is also easier than the ones presented before [6, 10-11].

\section{Acknowledgment}

The authors gratefully acknowledge the helpful comments and suggestions of the reviewers, which have improved the presentation.

\section{References:}

[1] AFSC: Software Risk Abatement, U. S. Air Force Systems Command, AFSC/AFLC pamphlet 800-45, Andrews AFB, MD, Sep. 1988, pp. 1-28.

[2] Boehm, B.W.: A Spiral Model of Software Development and Enhancement, Computer, May, 1988, pp. 61-72.

[3] Boehm, B.W.: Software Risk Management, CS Press, Los Alamitos, Calif.,1989

[4] Boehm, B.W.: Software Risk Management: Principles and Practices, IEEE Software 8, 1991, pp. 32-41.

[5] Charette, R.N.: Software Engineering Risk Analysis and Management, Mc Graw-Hill, New York, 1989 
[6] Chen, S.M.: Evaluating the Rate of Aggregative Risk in Software Development Using Fuzzy Set Theory, Cybernetics and Systems: International Journal 30, 1999, pp. 57-75.

[7] Conger, S.A.: The New Software Engineering, Wadsworth Publishing Co. Belmont, California, 1994

[8] Gilb, T.: Principles of Software Engineering Management, Addison-Wesley Publishing Co., New York, 1988

[9] Kaufmann, A. and Gupta, M.M.: Introduction to Fuzzy Arithmetic Theory and Applications Van Nostrand Reinhold, New York, 1991

[10] Lee, H.-M.: Applying fuzzy set theory to evaluate the rate of aggregative risk in software development, Fuzzy sets and Systems 79, 1996, pp. 323-336

[11] Lee, H.-M., Lee, S.-Y., Lee, T.-S. and Chen, J.-J.: A new algorithm for Applying fuzzy set theory to evaluate the rate of aggregative risk in software development, Information Sciences, vol.153, 2003, pp.177-197.

[12] Lin, L. and Lee, H.-M.: A Fuzzy Decision Support System for Selecting the Facility Site of Multinational Enterprises, International Journal of Innovative Computing, Information and Control, Vol. 3, No. 1, 2007, pp. 151-162.

[13] Sommerville, I.: Software Engineering, Sixth Edition, Pearson Education Limited, England, 2001

[14] Zadeh, L.A.: Fuzzy Sets, Information and Control 8, 1965, pp. 338-353.

[15] Zadeh, L.A.: The Concept of a Linguistic Variable and it's Application to Approximate Reasoning, Information Sciences 8, 1975, pp. 199249 (I), pp. 301-357 (II), 9, 1976， pp. 43-58 (III) [16] Zimmermann, H.-J.: Fuzzy Set Theory and Its Applications, Second Revised Edition, Kluwer Academic Publishers, Boston/Dordrecht/London, 1991

Table 1 Contents of the hierarchical structure model

\begin{tabular}{|c|c|c|c|c|c|c|c|c|c|c|}
\hline \multirow{2}{*}{ Attribute } & \multirow{2}{*}{\begin{tabular}{|l|} 
Risk \\
item \\
\end{tabular}} & \multirow[b]{2}{*}{ Weight-2 } & \multirow{2}{*}{ Weight-1 } & \multicolumn{7}{|c|}{ Linguistic variables } \\
\hline & & & & $\mathrm{V}_{1}$ & $\mathrm{~V}_{2}$ & $\mathrm{~V}_{3}$ & $\mathrm{~V}_{4}$ & $\mathrm{~V}_{5}$ & $\mathrm{~V}_{6}$ & $V_{7}$ \\
\hline \multirow[t]{2}{*}{$\mathrm{X}_{1}$} & & $\mathrm{~W}_{2}(1)$ & & & & & & & & \\
\hline & $\mathrm{X}_{11}$ & & $\mathrm{~W}_{1}(1,1)$ & $m_{11}^{(1)}$ & $m_{11}^{(2)}$ & $m_{11}^{(3)}$ & $m_{11}^{(4)}$ & $m_{11}^{(5)}$ & $m_{11}^{(6)}$ & $m_{11}^{(7)}$ \\
\hline \multirow[t]{4}{*}{$\mathrm{X}_{2}$} & $\mathrm{X}_{21}$ & $\mathrm{~W}_{2}(2)$ & $\mathrm{W}_{1}(2,1)$ & $m_{21}^{(1)}$ & $m_{21}^{(2)}$ & $m_{21}^{(3)}$ & $m_{21}^{(4)}$ & $m_{21}^{(5)}$ & $m_{21}^{(6)}$ & $m_{21}^{(7)}$ \\
\hline & $\mathrm{X}_{22}$ & & $\mathrm{~W}_{1}(2,2)$ & $m_{22}^{(1)}$ & $m_{22}^{(2)}$ & $m_{22}^{(3)}$ & $m_{22}^{(4)}$ & $m_{22}^{(5)}$ & $m_{22}^{(6)}$ & $m_{22}^{(7)}$ \\
\hline & $\mathrm{X}_{23}$ & & $\mathrm{~W}_{1}(2,3)$ & $m_{23}^{(1)}$ & $m_{23}^{(2)}$ & $m_{23}^{(3)}$ & $m_{23}^{(4)}$ & $m_{23}^{(5)}$ & $m_{23}^{(6)}$ & $m_{23}^{(7)}$ \\
\hline & $\mathrm{X}_{24}$ & & $\mathrm{~W}_{1}(2,4)$ & $m_{24}^{(1)}$ & $m_{24}^{(2)}$ & $m_{24}^{(3)}$ & $m_{24}^{(4)}$ & $m_{24}^{(5)}$ & $m_{24}^{(6)}$ & $m_{24}^{(7)}$ \\
\hline \multirow[t]{3}{*}{$\mathrm{X}_{3}$. } & & $\mathrm{W}_{2}(3)$ & & & & & & & & \\
\hline & $\mathrm{X}_{31}$ & & $\mathrm{~W}_{1}(3,1)$ & $m_{31}^{(1)}$ & $m_{31}^{(2)}$ & $m_{31}^{(3)}$ & $m_{31}^{(4)}$ & $m_{31}^{(5)}$ & $m_{31}^{(6)}$ & $m_{31}^{(7)}$ \\
\hline & $\mathrm{X}_{32}$ & & $\mathrm{~W}_{1}(3,2)$ & $m_{32}^{(1)}$ & $m_{32}^{(2)}$ & $m_{32}^{(3)}$ & $m_{32}^{(4)}$ & $m_{32}^{(5)}$ & $m_{32}^{(6)}$ & $m_{32}^{(7)}$ \\
\hline \multirow[t]{5}{*}{$\mathrm{X}_{4}$. } & & $\mathrm{W}_{2}(4)$ & & & & & & & & \\
\hline & $\mathrm{X}_{41}$ & & $\mathrm{~W}_{1}(4,1)$ & $m_{41}^{(1)}$ & $m_{41}^{(2)}$ & $m_{41}^{(3)}$ & $m_{41}^{(4)}$ & $m_{41}^{(5)}$ & $m_{41}^{(6)}$ & $m_{41}^{(7)}$ \\
\hline & $\mathrm{X}_{42}$ & & $\mathrm{~W}_{1}(4,2)$ & $m_{42}^{(1)}$ & $m_{42}^{(2)}$ & $m_{42}^{(3)}$ & $m_{42}^{(4)}$ & $m_{42}^{(5)}$ & $m_{42}^{(6)}$ & $m_{42}^{(7)}$ \\
\hline & $\mathrm{X}_{43}$ & & $\mathrm{~W}_{1}(4,3)$ & $m_{43}^{(1)}$ & $m_{43}^{(2)}$ & $m_{43}^{(3)}$ & $m_{43}^{(4)}$ & $m_{43}^{(5)}$ & $m_{43}^{(6)}$ & $m_{43}^{(7)}$ \\
\hline & $\mathrm{X}_{44}$ & & $\mathrm{~W}_{1}(4,4)$ & $m_{44}^{(1)}$ & $m_{44}^{(2)}$ & $m_{44}^{(3)}$ & $m_{44}^{(4)}$ & $m_{44}^{(5)}$ & $m_{44}^{(6)}$ & $m_{44}^{(7)}$ \\
\hline \multirow[t]{3}{*}{$\mathrm{X}_{5} \cdot$} & & $\mathrm{W}_{2}(5)$ & & & & & & & & \\
\hline & $\mathrm{X}_{51}$ & & $\mathrm{~W}_{1}(5,1)$ & $m_{51}^{(1)}$ & $m_{51}^{(2)}$ & $m_{51}^{(3)}$ & $m_{51}^{(4)}$ & $m_{51}^{(5)}$ & $m_{51}^{(6)}$ & $m_{51}^{(7)}$ \\
\hline & $\mathrm{X}_{52}$ & & $\mathrm{~W}_{1}(5,2)$ & $m_{52}^{(1)}$ & $m_{52}^{(2)}$ & $m_{52}^{(3)}$ & $m_{52}^{(4)}$ & $m_{52}^{(5)}$ & $m_{52}^{(6)}$ & $m_{52}^{(7)}$ \\
\hline \multirow[t]{2}{*}{$\mathrm{X}_{6}$. } & & $\mathrm{W}_{2}(6)$ & & & & & & & & \\
\hline & $\mathrm{X}_{61}$ & & $\mathrm{~W}_{1}(6,1)$ & $m_{61}^{(1)}$ & $m_{61}^{(2)}$ & $m_{61}^{(3)}$ & $m_{61}^{(4)}$ & $m_{61}^{(5)}$ & $m_{61}^{(6)}$ & $m_{61}^{(7)}$ \\
\hline
\end{tabular}


Table 2 Contents of the example

\begin{tabular}{|c|c|c|c|c|c|c|c|c|c|c|}
\hline \multirow[b]{2}{*}{ Attribute } & \multirow{2}{*}{\begin{tabular}{|l} 
Risk \\
item
\end{tabular}} & \multirow[b]{2}{*}{ Weight-2 } & \multirow[b]{2}{*}{ Weight-1 } & \multicolumn{7}{|c|}{ Linguistic variables } \\
\hline & & & & $\mathrm{V}_{1}$ & $\mathrm{~V}_{2}$ & $\mathrm{~V}_{3}$ & $\mathrm{~V}_{4}$ & $\mathrm{~V}_{5}$ & $\mathrm{~V}_{6}$ & $\mathrm{~V}_{7}$ \\
\hline \multirow{2}{*}{$X_{1}$. } & & 0.3 & & & & & & & & \\
\hline & $X_{11}$ & & 1 & 0 & 0.17 & 0.83 & 0 & 0 & 0 & 0 \\
\hline \multirow[t]{5}{*}{$X_{2}$} & & 0.3 & & & & & & & & \\
\hline & $X_{21}$ & & 0.4 & 0 & 0.53 & 0.47 & 0 & 0 & 0 & 0 \\
\hline & $X_{22}$ & & 0.4 & 0 & 0.89 & 0.11 & 0 & 0 & 0 & 0 \\
\hline & $X_{23}$ & & 0.1 & 0.25 & 0.75 & 0 & 0 & 0 & 0 & 0 \\
\hline & $X_{24}$ & & 0.1 & 0.61 & 0.39 & 0 & 0 & 0 & 0 & 0 \\
\hline \multirow[t]{3}{*}{$X_{3}}$. & & 0.1 & & & & & & & & \\
\hline & $X_{31}$ & & 0.5 & 0 & 0.17 & 0.83 & 0 & 0 & 0 & 0 \\
\hline & $X_{32}$ & & 0.5 & 0 & 0.53 & 0.47 & 0 & 0 & 0 & 0 \\
\hline \multirow[t]{5}{*}{$X_{4}$} & & 0.1 & & & & & & & & \\
\hline & $X_{41}$ & & 0.3 & 0 & 0.89 & 0.11 & 0 & 0 & 0 & 0 \\
\hline & $X_{42}$ & & 0.1 & 0 & 0.17 & 0.83 & 0 & 0 & 0 & 0 \\
\hline & $X_{43}$ & & 0.3 & 0 & 0.17 & 0.83 & 0 & 0 & 0 & 0 \\
\hline & $X_{44}$ & & 0.3 & 0 & 0.53 & 0.47 & 0 & 0 & 0 & 0 \\
\hline \multirow[t]{3}{*}{$X_{5}$} & & 0.1 & & & & & & & & \\
\hline & $X_{51}$ & & 0.5 & 0 & 0 & 0.81 & 0.19 & 0 & 0 & 0 \\
\hline & $X_{52}$ & & 0.5 & 0 & 0 & 0.81 & 0.19 & 0 & 0 & 0 \\
\hline$X_{6}$ & $X_{61}$ & 0.1 & 1 & 0 & 0.17 & 0.83 & 0 & 0 & 0 & 0 \\
\hline
\end{tabular}

